\title{
Methodical approach to assessing the effectiveness of the management system of thermal power plants in Russia
}

\author{
P. I. Okley ${ }^{1}, V . K$. Lozenko ${ }^{1}$ and $R$. I. Inamov ${ }^{1, *}$ \\ ${ }^{1}$ National Research University "Moscow Power Engineering Institute", Moscow, Russia
}

\begin{abstract}
Physical deterioration of thermal power plants based on hydrocarbon fuels leads to technological violations (TV) in their work. Low rates of renewal of thermal generation predetermines the further exploitation of old capacities. In this regard, the activity of the management of energy holdings (EH) is more focused on maintaining the equipment in working condition. The methods, approaches and tools underlying decision-making by the management of energy holding companies are different, respectively, the results of the functioning of the organized management systems (MS) of each company are also different. To assess the effectiveness of the management system it is proposed to use such a generalized indicator as the number of technological violations per year per $1 \mathrm{GW}$ of installed capacity.
\end{abstract}

\section{Introduction}

The electric power industry is one of the key areas of Russia's development, the country's economy and social position of all citizens depend on it. This industry is represented by 11 largest holding companies, which produce about $85 \%$ of electricity (in $2018-921.8$ billion $\left.\mathrm{kW}^{*} \mathrm{~h}\right)$ of the total annual production (1076.2 billion $\left.\mathrm{kW}^{*} \mathrm{~h}\right)$ [1]. The existing production structure has been observed over the last 4-5 years, and in the future will change little. Information on the volume of electricity production in 2018 is presented in figure 1.

The electric power complex of the Russian Federation is a differentiated structure of generating capacity - for example, the balance of the largest holdings includes both traditional thermal power plants and nuclear and hydro generation. To understand the scale of management activities it is interesting to find out he general values of the installed capacity belonging to each holding in addition to data on production volumes and the technological structure of the generating complex of the Russian Federation. The values of installed capacities of the largest energy holdings of the Russian Federation are presented in figure 1.

Similar to the production of electricity, 11 companies in Russia own more than $85 \%$ (211.3 GW) of generating facilities out of a total of $243.24 \mathrm{GW}$ [1]. The power plants of these companies were largely inherited as a

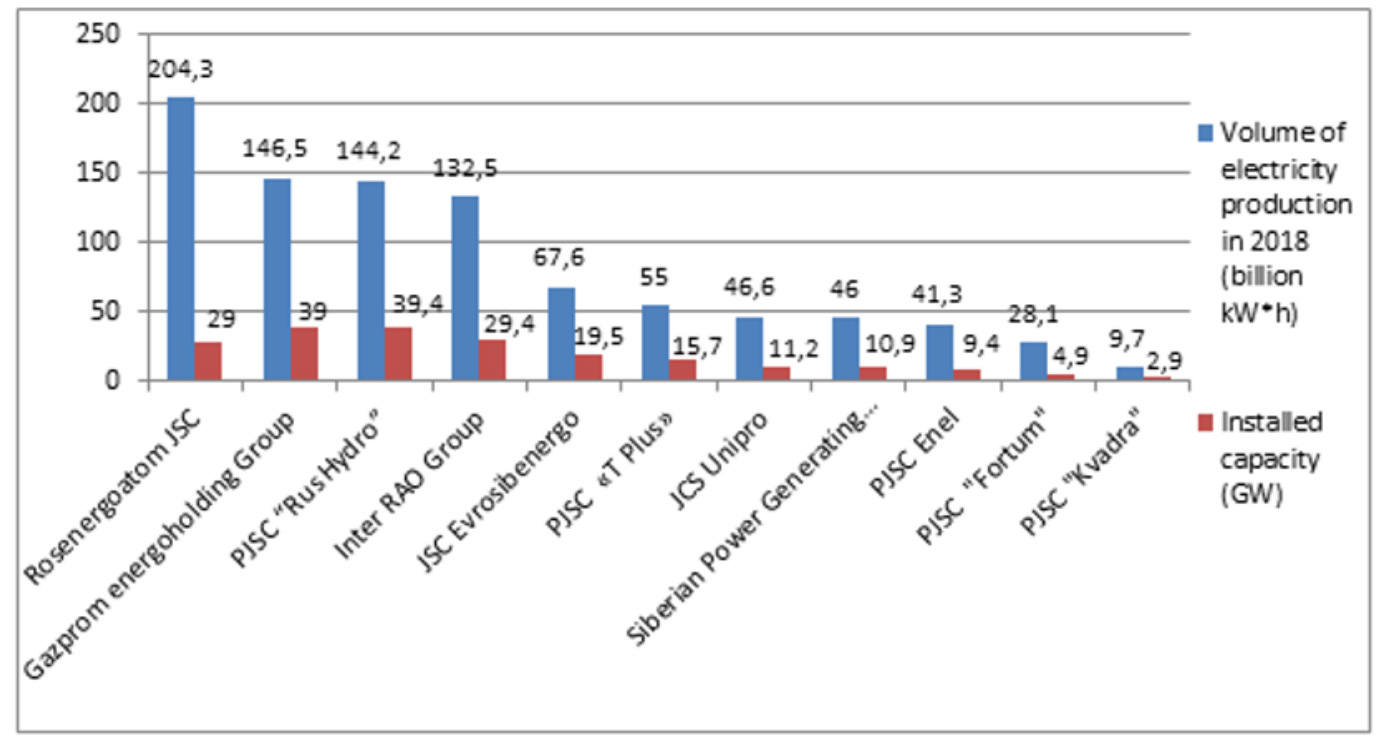

Figure 1. Electricity production volumes and installed generation capacity of energy holdings of the Russian Federation.

\footnotetext{
* Corresponding author: infogia2014@yandex.ru
} 
result of industry restructuring in order to create a liberalized market and attract investments to modernize outdated generation. The distribution of thermal power plants on hydrocarbon fuels (steam power plants (SPP), steam and gas plants (SGP) and gas turbine plants (GTP)) was carried out on a technological basis and taking into account the age characteristics of power plants so that the energy holding companies after the reform were in the same conditions for operating activities. The power plants of energy companies should have approximately the same average age and condition of the energy facilities.

However, this method did not apply to nuclear and hydropower, so it forced the situation that nuclear power plants remained under control of JSC "Rosenergoatom Concern" and a significant part of the hydropower plants is managed by the organization PJSC "RusHydro" [2, 3]. The basis of this decision was the desire to focus the activities of organizations management on the vector of sustainable development only in one production technology, within which all efforts should be aimed at ensuring the reliability and safe operation of nuclear power plants and hydropower plants under the direct supervision of the state companies. In other words, the increased danger objects in comparison with traditional thermal power plants remained under state control, within the framework of the share capital structure (Russian government owns $60.5 \%$ of PJSC "RusHydro" shares and $100 \%$ of JSC "Rosenergoatom Concern" [4, 5]).

As mentioned above, the reform was aimed to resuscitate the Russian electric power industry, due to its stagnation in the area of updating production assets and increasing accident rates, the difficulties of ensuring reliable operation. Therefore, characterizing the power industry of Russia, one should tell about the technical condition of generation facilities.

According to "Rosstat" estimates, by the end of 2017, the fixed assets of the industry in the field of electricity supply, on average, have a residual life of the main equipment of about $29.6 \%$ of the total service life [6].

The average age of the generating facilities of the United Energy System of Russia is about 34 years, and the excess rate of the standard park resource is 1.57 r.u. $[7,8]$. The specialists of the Ministry of Energy calculated that in order to maintain the current average age and depreciation of thermal power plants until 2035, it is necessary to commission $2.4 \mathrm{GW}$ of new capacity annually, in case of decommissioning of the oldest units [8]. An information regarding the age characteristics of power plants by types of thermal generation is very interesting. The average age of thermal power plants on steam-powered equipment is 40 years, combined-cycle units is 7.4 years, and gas and turbine units is 12.5 years. It is not difficult to understand that most traditional thermal power plants have long been functioning outside the park resource.

The average age of the equipment is a calculated indicator, which has statistical value, therefore, as more representative information, it is advisable to consider the actual age structure of the TPP. According to [9], about $46 \mathrm{GW}(65 \%)$ of thermal power plants in Russia work in the condensation cycle are older than 30 years, when the combined heat and power plant of this age value reached $53.6 \mathrm{GW}(59 \%)$ of capacity. Thus, $61.9 \%(99.8 \mathrm{GW})$ of the total heat generation of the Unified Energy System of Russia operates outside of its park resource. As for the relatively new thermal capacity, only $34.5 \mathrm{GW}$ of TPPs have a working time of up to 20 years inclusive.

The indicators of the equipment conditions affect its reliability characteristics. Ensuring reliable operation of production facilities is one of the priorities of the of sustainable development concept of the electric power industry. However, it is quite difficult to achieve this, since the increase in the performance of individual parts of thermal generation causes the accumulation of many different defects associated with changes in the properties of metals due to high temperatures and pressures.

Operation of predominantly obsolete equipment is the reason for maintaining a high level of the number of technological disruptions (TD), the consequences of which are the occurrence of failures of production assets (PA), de-energizing of entire energy districts, the allocation of regional power systems for independent work, as well as injuries or people deaths.

The retrospective dynamics of changes in the number of technological violations at thermal generation facilities is generally positive, but not sufficient. According to information [10] provided by the Ministry of Energy, the number of TDs for 2018 was 3091 cases, when 4 years ago this figure was 4305 .

The lack of funds for the active large-scale construction of new generating capacities implies the long-term operation of generating companies on obsolete equipment, which partly undermines the country's energy security. The presented industry problems focus most of the activity of energy holdings management on improving the reliability indicators of the PA and maintaining them in working condition from the position of the minimum cost of the equipment life cycle [11]. The last is due to the need of the organization to make a profit. The main processes involve the use of modern approaches to the planning of repair activities, maintenance of PA [12, 13], conducting a reliable assessment of the current state of equipment and forecasting the development of $\mathrm{TP}$ and their consequences. The higher the level of management decisions developed and the more carefully organized the approach to reliability management, which is based on mathematical calculations, identified dependencies of failures, the less likely the occurrence of technological violations [14-17]. Reducing the value of TP means lowering the total cost of ownership of the assets, as a result of which the organization benefits in the form of strengthening economic and competitive positions.

Technological violations in the context of a causal relationship in the overwhelming majority of cases include the human factor, since any technical device forms a human-machine system. The human factor in the realities of the electric power industry of the Russian Federation is mainly determined by incorrect management actions, poor quality preventive actions for the occurrence of a heat pump, as well as untimely 
planning of these actions, due to the lack of effective forecast models of the technical condition of facilities. As a result, this leads to the conclusion that an increase in the number of TPs is a consequence of an inefficiently organized management system [14-18].

The information presented in Table 1 shows that when working mainly on old equipment, the low rates of commissioning new capacities still managed to achieve positive results. First of all, the revealed dynamics is determined by the increased quality of activity of the management of organizations. Of course, this was influenced by the integration of international standards (MS ISO 9001, ISO 14000, OHSAS 18001, ISO 50001, ISO 55001, ISO 45001) into the practice of managing electricity generating companies, but this is not the only reason for reducing the accident rate. The solutions developed by management are the result of the application of scientific methods and research in the field of identifying patterns and prerequisites for failures. The management of energy holdings has initiated the organization of research centers, where, with the participation of top management, new methods of improving reliability, both purely technical and managerial, are being developed. The development of mathematical modeling of technical objects made it possible to increase the effectiveness of forecasts for the occurrence of TP and prevent them at the lowest cost by repairing, replacing individual parts or complete reconstruction $[11,18]$.

\section{Methods}

Energy holdings operate on the basis of uniquely designed management systems, the quality of which depends on the competencies of management. In view of the individual characteristics and level of development of methods and decision-making tools in the field of operation of energy facilities, the results of the work of the holdings management, as a rule, are different. Since all the companies under consideration have a common functionality, the task of assessing the effectiveness of their management systems on the basis of measurable indicators arises.
Taking into account the leadership focus on ensuring reliable operation of the $\mathrm{PA}$, reducing the operational costs of maintaining the equipment and generating maximum profit, the approach to assessing the effectiveness of management activities can be based on information on the number of technological violations.

The valuation approach directly consists in calculating the specific value of the number of TP (x) per unit of installed capacity of energy holding companies (industry) facilities (P). The formula for performing calculations is as follows:

$$
X=\frac{T}{P}
$$

where $\mathrm{T}$ - is the number of technological violations for a selected period of time $t, T P ; P$ - the amount of installed capacity of a single organization, GW.

On the basis of the adopted indicator, it is proposed to assess the level of reliability of thermal generation, which the management system provides, both for the industry as a whole (its integral result taking into account the contribution of each organization), and using energy holdings as an example, as well as the integral value of the remaining part of smaller generating companies (GC). The results of the assessment are presented in Table 1 based on the information provided to the Ministry of Energy (subject to authenticity) [10].

\section{Results}

About $74 \%$ of thermal generation in Russia belongs to the organizations represented in the table 1, when the remaining $26 \%$ of TPPs are controlled by a smaller group of companies. According to the results obtained over the course of 5 years, all the largest power energy holdings operating thermal power plants demonstrate a positive trend in reducing the number of TPs by $1 \mathrm{GW}$. As for small GC, the integral specific values of the amount of TP obtained for them are practically unchanged. This allows us to say about the absence of directed actions to increase the reliability of the functioning of objects. The outsider among the largest power energy holdings is PJSC "Quadra", whose

Table 1. The results of the evaluation of the specific value of technological violations.

\begin{tabular}{|l|l|l|l|l|l|}
\hline & \multicolumn{5}{|c|}{ The specific value of the number of TP, } \\
\hline & \multicolumn{1}{|c|}{ TP/GW } \\
\hline Organizations / Years & $\mathbf{2 0 1 4}$ & $\mathbf{2 0 1 5}$ & $\mathbf{2 0 1 6}$ & $\mathbf{2 0 1 7}$ & $\mathbf{2 0 1 8}$ \\
\hline JCS Unipro & 12,66 & 11,66 & 9,68 & 6,13 & 6,42 \\
\hline Gazprom energoholding Group & 22,94 & 19,61 & 18,11 & 14,96 & 10,7 \\
\hline Inter RAO Group & 20,98 & 18,00 & 16,73 & 14,83 & 12,25 \\
\hline Siberian Power Generating & 27,26 & 28,78 & 18,59 & 15,92 & 12,84 \\
\hline PJSC "Enel Russia" & 28,83 & 29,26 & 22,21 & 16,13 & 15,81 \\
\hline PJSC "Fortum" & 24,63 & 20,4 & 21,87 & 13,86 & 16,29 \\
\hline PJSC «T Plus» & - & - & 30,96 & 21,67 & 17,45 \\
\hline PJSC "Kvadra" & 70,66 & 55,94 & 60,27 & 71,62 & 51,05 \\
\hline $\begin{array}{l}\text { All sectoral GCs including deduction of the contribution of } \\
\text { energy holdings }\end{array}$ & 34,81 & 32,75 & 32,15 & 36,22 & 34,68 \\
\hline $\begin{array}{l}\text { All sectoral GCs, taking into account the contribution of } \\
\text { energy holdings }\end{array}$ & 27,17 & 25,67 & 23,42 & 21,93 & 18,78 \\
\hline
\end{tabular}


performance is 2.9 times worse than that of its closest competitor in Table 1 - PJSC "T plus". At the same time, PJSC "Quadra" lags 1.47 times behind the indicator of a small group of companies. The total value of the specific amount of TP in the industry is at the level of 18.78 $\mathrm{TP} / \mathrm{GW}$, which is mainly ensured by the significant contribution of power energy holdings, since this indicator for the remaining branch of the industry is $34.68 \mathrm{TP} / \mathrm{GW}$.

It is important to note that any fact of the emergence of a TP determines what economic damage the energy holding will incur. Modern management seeks to solve the problem of not how much a decrease in the number of TPs, how much of minimizing economic damage, which is very important in the conditions of a financial deficit. Initially it may seem that the smaller the number of TPs, the less and the damage from them, but in reality the non-linear relationship between the two indicators is revealed. And this is due to the fact that the power industry has technological violations of various scales.

The scale of TP is the determining factor in the value of economic damage. The most serious TP, as a rule, are accompanied by fires, explosions. The economic damage from an emergency incident that occurred at the beginning of 2015 at Surgut GRES-2 (owned by JSC "Unipro"), which resulted in a fire and collapse of about $1,300 \mathrm{~m} 2$ of the roof, amounted to about 1 billion rubles [11]. In 2016, due to the fire at Berezovskaya GRES (owner of JSC "Unipro"), a new power unit put into operation in 2015 was subjected to significant damage the economic damage amounted to more than 20 billion rubles, and this is without taking into account the cost of rehabilitation works. However, the damage from TP is not always so significant. Take, for example, the accident at the combined heat and power plant HovuAksy in 2012, where the heating pipe broke - the damage was estimated at 78 million rubles, which is 12.8 times less than at Surgut GRES-2 [11]. In other words, the number of TPs can steadily decrease, and the integral assessment of economic damage to increase, or remain at the same level - this first of all makes it clear that the proportion of large (most costly) TPs relative to the total mass has increased.

A reduction in the number of TPs can certainly be considered a positive result of the management's work in fact, the number of proceedings, discussions, time spent on drawing up reports, directions of commission groups (all that hinders management's focus on achieving the main goals of the company) and the increase in PA reliability. But the lack of information on the significance of economic damage during the assessment does not fully reflect the work done by the management. Its best result is a reduction in the specific value of the amount of TP and economic damage. With a decrease in the specific value of the quantity of TP, but an increase in the damage, the activity of the management is formal - there is no concentrated work aimed at minimizing the probability of occurrence of serious TP.

The best performance is demonstrated by the organizations: JSC "Unipro", LLC "Gazprom Energoholding" and PJSC "Inter RAO". The high rate of
JSC "Unipro" in comparison with LLC "Gazprom Energoholding" and PJSC "Inter RAO" is 1.66 times and 1.9 times, respectively, due to the relatively low installed capacity $(10.43 \mathrm{GW})$, a small number of power plants $(5$ TPPs) and the presence of $1620 \mathrm{MW}$ of new capacity. When PJSC "Inter RAO and LLC "Gazprom Energoholding" manage 2.82 and 3.72 times, respectively, the greater installed capacity. The effect of the scale of business in this case plays an important role, since ensuring the reliability of a large number of old generating capacity is much more difficult than managing 5 power plants. Therefore, comparing company data is not advisable. In accordance with the accepted assumption, the management systems of LLC "Gazprom Energoholding" and PJSC "Inter RAO" can be considered the best in the practice of ensuring the reliability of energy facilities. During the assessment, the achieved result of LLC "Gazprom Energoholding" in 2018 will be used as the baseline.

The specific value of the amount of TP at the facilities of LLC "Gazprom Energoholding" is 10.7 $\mathrm{TP} / \mathrm{GW}$, which makes it possible to assign the highest value to the management system of the company -1.0 r.u. Using the relative method, we will get an assessment of the performance of the PJSC "Inter RAO" - 0.87 r.u. Since the integral result of the activities of small GCs is 34.68 TP (224.1\% more), the level of their management systems is 0.3 r.u. The complex value of the specific quantity of heat pump for electric power is -0.569 r.u.

\section{Discussion}

Assigning the estimated values, it is important to understand whether the high assessment of the management systems of the two power energy holdings corresponds to reality by correlating the specific value of the amount of TP and the value of economic damage, taking into account the cost of equipment repairs for the reporting year. The need to operate with repair costs is explained by the fact that PA management in terms of the minimum cost of ownership implies an assessment of the total cost of repairs and possible damage. In other words, the task of management is to ensure that this amount is minimized. Unfortunately, information on economic damages and costs for repairs are given only by PJSC "Inter RAO". Table 2 summarizes all available economic indicators, taking into account their reduction to 2014 prices [19].

In 2018, economic damage decreased by more than 2 times compared to 2014 indicators. And this is despite the fact that the organization only by $12.25 \%$ (1242 million rubles) increased repair costs. In general, the economic effect of the management's actions amounted to 357 million rubles in 2018. Based on the information provided, it can be said that the management system of PJSC "Inter RAO" demonstrates good results justifying the assessment assigned to it, not only from the standpoint of the specific value of the amount of TP, but also economic results.

In conclusion, it is important to note that not only the amount of TP per unit of power reflects the effectiveness 
Table 2. Economic damage from TP in PJSC «Inter RAO».

\begin{tabular}{|c|c|c|c|c|}
\hline Period, year & $\begin{array}{c}\text { The number of TP } \\
\text { (units) }\end{array}$ & $\begin{array}{c}\text { The economic damage } \\
\text { from the TP in view of } \\
\text { inflation, (mln. rub.) }\end{array}$ & $\begin{array}{c}\text { The cost of repairs } \\
\text { and operation of } \\
\text { PA (mln. rub.) }\end{array}$ & $\begin{array}{c}\text { Total costs } \\
\text { (mln. rub.) }\end{array}$ \\
\hline $\mathbf{2 0 1 4}$ & 610 & 3138 & 10133 & 13271 \\
\hline $\mathbf{2 0 1 5}$ & 522 & 2266 & 10043 & 12309 \\
\hline $\mathbf{2 0 1 6}$ & 473 & 1858 & 8923 & 10781 \\
\hline $\mathbf{2 0 1 7}$ & 422 & 2734 & 10500 & 13235 \\
\hline $\mathbf{2 0 1 8}$ & 361 & 1538 & 11375 & 12914 \\
\hline
\end{tabular}

of management work and can be estimated in a relative way. As estimated indicators of competitiveness in modern energy, it is also advisable to operate with the specific value of the conditional fuel consumption, the specific capitalization of the company, the value of its shares. By applying the proposed methodology to these components, by means of an integral calculation, it is possible to obtain a more complete description of the results of the work of the management.

\section{References}

1.The largest electric power companies in Russia. Ministry of Energy of the Russian Federation. [Electronic resource]. Access mode: https://minenergo.gov.ru/node/4846 (the date of access 03/05/2019) (2019)

2.History of the company PJSC RusHydro. [Electronic resource]. Access mode: http://www.rushydro.ru/company/history/ (the date of access 03/05/2019) (2019)

3. The history of the company JSC Rosenergoatom Concern. [Electronic resource]. Access mode: http://www.rosenergoatom.ru/about/istoricheskayaspravka/ (the date of access 03/05/2019) (2019)

4. Share capital of JSC Rosenergoatom Concern. [Electronic resource]. Access mode: http://www.rosenergoatom.ru/shareholders/aktsionernyykapital/index.php?sphrase_id $=33875$ (the date of access 03/05/2019) (2019)

5. Share capital of PJSC RusHydro 2019. [Electronic resource]. Access Mode: http://www.rushydro.ru/investors/stockmarket/capital/ (the date of access 05/05/2019)

6. E.P. Grabchak, I.A. Baikov, E.A. Medvedeva, P.A. Dunaev, The main results of the operation of electric power facilities in 2016. The results of the passage of the 2016-2017 APR. Tasks for the medium term. Ed. Deputy Minister of Energy of the Russian Federation 104 (2017)

7. Informational and analytical report On the operation and development of the electric power industry in 2011. Ministry of Energy of the Russian Federation. [Electronic resource]. Access mode: https://minenergo.gov.ru/node/3399 (the date of access 05/19/2019) (2011)

8. A.B. Zhikharev and N.Y. Posypanko, Research "Modernization of thermal power plants: Maneuver evasion from the market?" Consulting company VYGON Consulting (2017)
9. ITS 38-2017 2017 Burning fuel in large installations for energy production. (Moscow: Bureau of BAT)

10. Information on accidents in power grids and generation. Ministry of Energy of the Russian Federation 2019. [Electronic resource]. Access mode: https://minenergo.gov.ru/node/267 (the date of access 20/05/2019).

11. P.I. Okley, Economic-mathematical methods and models for the design of programs of repair work at thermal power plants (Moscow: Lenand) 266 (2017)

12. GOST R ISO 9001-2015 2015 Quality management systems. Requirements (Moscow: Standartinform) 48

13. GOST R 55.0.01-2014/ISO 55000:2014 2015 Asset Management. National System of Standards. General understanding, principles and terminology (Moscow: Standartinform) 17

14. P.I Okley, Prediction of residual life and the probability of equipment failure is the basis for the design of the production program of repair work of a thermal power plant Controlling 65, 54-63 (2017)

15. P.I. Okley Process approach to change management in organizations. Innovation in management 4, 38-44 (2017)

16. P.I. Okley, Matrix model of the study of capital gains and the period of change of equipment of thermal power plants Economic analysis: theory and practice 1, 159-183 (2016)

17. P.I. Okley, Evaluation of the management efficiency of thermal power plants Economy of sustainable development 1, 303-309 (2016)

18. P.I. Okley, Principles of forming a distributed knowledge base for TPPs of energy corporations of Russia Innovative activity 2, 30-35 (2016)

19. Website of the energy holding PJSC "Inter $R A O$ " Access mode: https://www.interrao.ru/ (the date of access 05/24/2019) (2019) 